\title{
O significado da autoavaliação institucional na perspectiva de técnicos-administrativos de uma universidade pública
}

\author{
Ana Elisa de Souza Falleiros \\ Márcio Lopes Pimenta \\ Valdir Machado Valadão Júnior
}

Resumo: Em 2004, o Ministério da Educação criou o Sistema Nacional de Avaliação do Ensino Superior como uma forma de regular as Instituições de Ensino Superior e avaliar a qualidade da educação no Brasil. Este trabalho tem como objetivo principal analisar os significados atribuídos à Autoavaliação institucional pelos técnicos-administrativos da classe E com função gratificada da Universidade Federal de Uberlândia, considerando a perspectiva de integração, diferenciação e fragmentação. Utilizando como método de procedimento o estudo de caso e entrevistas em profundidade, foram coletados os discursos dos servidores para identificar os significados atribuídos à Autoavaliação Institucional em diferentes momentos. A análise de conteúdo evidenciou que na Universidade Federal de Uberlândia ainda não se tem uma cultura de avaliação e, um dos motivos para isso, é a falta de resultados práticos advindos do processo de avaliação.

Palavras-chave: Cultura organizacional. SINAES. Autoavaliação institucional. Administração pública.

The meanings of institucional self-assessment for the technical-administratives in a public university

Abstract: The Brazilian Ministry of Education created in 2004 the National Assessment of Higher Education as a system to regulate high level education institutions and evaluate the quality of education in Brazil. The objective of this study is to analyze the meanings attributed to institutional evaluation by technical-administrative class E with financial bonus at Federal University of Uberlândia, considering the perspective of integration, differentiation and fragmentation. Methods employed include case studies and in-depth interviews with public employees performed at two different times (2009 and 2013), in order to identify a change in perception over time. The content analysis evidenced that Federal University of Uberlândia does not have an evaluative culture and one of the reasons for this is the lack of practical results arising from the evaluation processe more prepared to make teaching-learning students with disability in inclusive education perspective.

Key words: Organizational culture. SINAES. Institutional Self-assessment. Public management. 


\section{Introdução}

Uma organização pública deve ter compromisso com resultados eficazes e com o público. Isso significa que ela deve democratizar o acesso em todos os níveis, ser permeável ao controle da sociedade, melhorar a qualidade dos serviços prestados e aumentar o grau de resolução dos problemas. Sendo assim, os processos de avaliação da administração pública tornam-se estratégicos para o seu gerenciamento (SIQUEIRA, 1990).

A administração pública no Brasil passou por três momentos históricos: a administração pública patrimonialista, a burocrática na segunda metade do século XIX e a gerencial na segunda metade do século XX. O último modelo surgiu como uma resposta a mudanças como a globalização da economia e o desenvolvimento tecnológico. Esse estilo tem foco nos resultados e não nos processos. O cidadão é visto como cliente dos serviços públicos e, por isso, os resultados são avaliados por meio do atendimento das suas necessidades (RAMOS, 2005).

A avaliação institucional implantada nas Instituições de Ensino Superior (IES) considera a avaliação não como um fim em si, mas como parte de um conjunto de políticas públicas, na área da educação superior, contribuindo para um processo mais amplo de revalorização dessa educação e de desenvolvimento da sociedade brasileira. A avaliação centraliza, organiza e dá coerência a esse processo (INEP, 2004). A atual avaliação institucional surgiu a partir da criação do Plano Nacional de Educação (PNE) criado por meio da Lei 10.172 de 9 de janeiro de 2001(BRASIL, 2001). Em 2004 é promulgada a Lei 10.861 de 14 de abril de 2004 que institui o Sistema Nacional de Avaliação da Educação Superior - SINAES (INEP, 2004).

Na atual avaliação institucional feita nas IES é necessário que os sujeitos envolvidos entendam o seu real significado e não a vejam como, meramente, um programa que deve ser cumprido, para que a universidade se integre ao sistema de educação superior. Essa integração vai muito além da ideia de simplesmente fazer parte. A partir desse entendimento, será possível traçar políticas e estratégias de desenvolvimento para a organização.

Conforme o INEP (2009, p. 113) o Governo tem procurado dar significado à avaliação desde a criação do PAIUB em 1993 que, mesmo com sua curta duração, contribuiu para tal e promoveu mudanças no cotidiano das Universidades. É evidenciado que "[...] a autoavaliação institucional deve ter, portanto, um caráter educativo, de melhora e de autorregulação. Deve buscar compreender a cultura e a vida de cada instituição em suas múltiplas manifestações". 
Nesse sentido, o estudo das três perspectivas de Martin (2002) - integração, fragmentação e diferenciação - colabora para a compreensão da cultura organizacional que permeia as Instituições Federais de Ensino Superior. Por meio dessa perspectiva, é possível evidenciar tanto a cultura dominante quanto as subculturas presentes na organização, de forma que elas possam ser entendidas e trabalhadas para a consecução de um objetivo.

O objetivo geral deste estudo é analisar os significados atribuídos à avaliação institucional pelos técnicos-administrativos da classe $\mathrm{E}$ com função gratificada da Universidade Federal de Uberlândia, considerando a perspectiva de integração, diferenciação e fragmentação.

$\mathrm{Na}$ Universidade Federal de Uberlândia, a avaliação institucional teve como objetivo identificar suas condições de ensino, pesquisa e extensão, suas potencialidades e fragilidades, com vistas à melhoria da sua qualidade por meio do redirecionamento do planejamento, das ações das Unidades Acadêmicas e Administrativas e da gestão da Universidade.

Do ponto de vista prático, o presente trabalho justifica-se por ser necessário entender e analisar como a avaliação de uma instituição pública é realmente vista pelos seus servidores, procurando relacionar os discursos destes com os objetivos do Governo ao implantar uma avaliação institucional. Também se justifica do ponto de vista teórico pelo fato de não haver sido encontrada na literatura nenhuma pesquisa sobre a avaliação institucional em IES que estude os seus significados, agrupando-os conforme a teoria de Martin (2002).

\section{Referencial teórico}

\subsection{A administração pública}

Para conceituar administração pública é necessário voltar-se para o direito administrativo. Di Pietro (2005, p. 99) conceitua a administração pública em dois sentidos: um subjetivo e outro objetivo. O primeiro envolve as pessoas, órgãos e agentes públicos que exercem a atividade administrativa. Já no sentido objetivo, ela engloba a natureza das atividades dos entes públicos e é atribuída aos órgãos do Poder Executivo.

A administração pública no Brasil vem se modificando, historicamente, por meio de três modelos: a administração pública patrimonialista, a burocrática e a gerencial. A administração pública patrimonialista tem como características principais a corrupção e o nepotismo, devido ao fato do estado ser a extensão do poder do soberano e os servidores, seus súditos. Esse modelo não se sustentou 
por muito tempo, surgindo a administração pública burocrática. Seus princípios orientadores eram: a profissionalização, a ideia de carreira, a hierarquia funcional, a impessoalidade e o formalismo. A administração pública burocrática sempre enfatizou o controle dos abusos, porém era ineficiente, pois não era voltada para servir o cidadão (RAMOS, 2005).

Conforme o mesmo autor devido às mudanças como a globalização da economia e o desenvolvimento tecnológico, surge a administração pública gerencial. Apesar de possuir alguns princípios da burocrática, ela inova na forma de controlar, passando a focar nos resultados e não nos processos. Ela vê o cidadão como cliente dos seus serviços e, por isso, os resultados são avaliados por meio do atendimento das necessidades do cidadão. Nesse modelo os objetivos do administrador público são precisos, existe autonomia na gestão dos recursos humanos, materiais e financeiros e controle ou cobrança a posteriori dos resultados.

É possível pensar que a administração pública no Brasil se encontre no modelo de administração pública gerencial, porém, ainda com algumas características da burocrática, como por exemplo, o foco nos processos e não nos resultados. Nota-se por parte do Governo Federal uma tentativa de mudar esse foco e, por isso, se torna necessário e importante criar mecanismos para se avaliar a administração pública.

\subsection{Avaliação institucional}

Holanda (2003, p. 2) propõe dois conceitos de avaliação: um no sentido lato e outro no estrito. No sentido lato a avaliação significa "julgar, estimar, medir, classificar, ordenar, ponderar, aferir ou analisar criticamente o mérito, o valor, a importância, a relevância ou a utilidade de algo ou alguém”. Já no sentido estrito, avaliar é "determinar o mérito e a prioridade de um projeto de investimento ou de um programa social, geralmente financiado com recursos públicos e voltado para resolver um determinado problema econômico ou social".

Mokate (2002) afirma que uma avaliação procura criar valor para alguma coisa, seja um programa, uma empresa, uma atividade ou um projeto. Para o autor a avaliação ainda não possui uma ferramenta significativa dentro das empresas para implementar e desenhar estratégias, programas e projetos.

Perez e Famá (2003) afirmam que no processo de avaliação se trabalha com premissas e hipóteses comportamentais, ou seja, ativos intangíveis. Ao se avaliar uma empresa, deve-se levar em consideração o valor dos ativos intangíveis, como por exemplo, o conhecimento dos funcionários. Apesar de 
não se ter ferramentas unânimes para medi-los, eles são considerados valiosos e estratégicos. Por isso, os autores Colauto e Beuren (2003), acreditam que um sistema de avaliação só será útil na tomada de decisões se for possível comparar os indicadores com outras empresas do mesmo setor ou com dados históricos da organização.

Neste estudo adotaremos a definição de avaliação institucional dada por Dias Sobrinho (1996, p. 72):

Avaliação implica um fundamentado conhecimento daquilo sobre o que interrogamos e atribuição de significado aos fatos, dados e informações que colhemos. Para além dos fatos, e a partir deles, a produção dos juízos de valor. Avaliar é uma ação que não admite neutralidade. Ultrapassa as descrições objetivas e as análises de coerência interna da realidade tomada como objeto. É um processo de forte conteúdo ético, pois indaga sobre valores e significados sociais. Atribuir significações e emitir juízos de valor, ou seja, avaliar, é reconhecer o mundo da produção humana e as diferenças, é responder às perguntas que fazemos a respeito de seus valores ou de suas qualidades.

Ainda conforme o mesmo autor, a avaliação deve lidar com os posicionamentos diferentes e não buscar a homogeneidade de valores, interesses ou concepções. A sua legitimidade depende da transparência do processo avaliativo. Portanto, toda instituição deve passar por processos de avaliação para que deixe de lado os juízos de valor e possa, com dados concretos e objetivos, traçar estratégias e gerir a diversidade internamente, bem como adaptar-se às necessidades do ambiente externo.

\subsubsection{Autoavaliação Institucional nas IFES: um braço do Sistema Nacional de Avaliação do Ensino Superior}

As primeiras avaliações institucionais do ensino superior surgiram com o intuito de controlar a qualidade das Instituições de Ensino Superior (IES) e prestar contas à sociedade. Em 1983 surgiu o PARU que abordou dois temas nos questionários aplicados: gestão e produção (disseminação de conhecimentos). Depois tem-se o Programa de Avaliação Institucional das Universidades Brasileiras - PAIUB que foi o primeiro programa de avaliação institucional das IES e a adesão a ele era voluntária. Após essa segunda tentativa de avaliação, surgiram outros mecanismos, porém mais focados nos resultados e desempenho das IES (POLIDORI; FONSECA; LARROSA, 2007).

A atual avaliação institucional faz parte do Sistema Nacional de Avaliação da Educação Superior (SINAES). Suas finalidades são a melhoria da qualidade da 
educação superior, a orientação da expansão da sua oferta, o aumento permanente da sua eficácia institucional e efetividade acadêmica e social e, especialmente, a promoção do aprofundamento dos compromissos e responsabilidades sociais das instituições de educação superior, por meio da valorização de sua missão pública, da promoção dos valores democráticos, do respeito à diferença e à diversidade, da afirmação da autonomia e da identidade institucional. O SINAES é composto por três componentes principais: a avaliação das instituições, dos cursos e do desempenho dos estudantes (INEP, 2004).

A avaliação institucional está dividida em duas modalidades: a autoavaliação e a avaliação externa. A primeira é feita pela Comissão Própria de Avaliação de cada IES e orientada pela Comissão Nacional de Avaliação da Educação Superior (CONAES). A segunda modalidade consiste em uma avaliação externa realizada por comissões designadas pelo INEP e é feita de acordo com padrões de qualidade para a educação (INEP, 2004).

Leite (2008), em seu artigo, evidencia a importância de se ter uma cultura de avaliação dentro da instituição de ensino superior. O estudo de Andriola e Souza (2010) corrobora com a ideia de Leite (2008) sobre a cultura de avaliação, pois os segmentos entrevistados evidenciam em seus discursos a importância da cultura avaliativa para entender a Avaliação Institucional e para que os sujeitos envolvidos participem dos ciclos de avaliação.

Com o SINAES, o Estado procurou consolidar um significado para a avaliação dentro das IES por meio de um processo contínuo, que serve, também, como forma de regulação do ensino superior. A seguir, se discutirá sobre pesquisas na área de cultura organizacional. Com isso, se pretende entender como a cultura de uma organização influencia nos modos de agir de seus colaboradores e pode interferir em como ela será gerida e seus objetivos traçados e alcançados.

\subsection{Cultura organizacional}

O tema cultura organizacional se popularizou nas últimas décadas. Foi a partir dos anos 80 que se notou o crescimento das pesquisas na área, apesar de já existir produção antes dessa data. Esse crescimento é explicado por dois fatores: o milagre japonês e o fato da cultura organizacional passar a ser vista como solução para problemas identificados dentro das empresas (FREITAS, 1991).

Martin (2002) relata que muitos estudiosos de cultura organizacional encontraram nela a possibilidade de obter soluções gerenciais para motivar e gerenciar os funcionários, utilizando valores da cultura para gerar comprometimento e aumentar a produtividade. A autora acredita que as pesquisas sobre a cultura organizacional têm mais a oferecer do que apenas promessas da cultura como 
forma de se chegar à lucratividade. Essa não é a única razão para se estudar cultura, porém, Martin (2002) admite que são pesquisas representativas.

No presente trabalho, utilizaremos a definição de cultura organizacional proposta por Martin (2002). A autora acredita que a cultura é uma metáfora usada para estudar a vida organizacional. Ela busca entender como as pessoas interpretam os significados das manifestações e como essas interpretações formam padrões de claridade, consistência e ambiguidade os quais podem ser utilizados para analisar a vida no ambiente de trabalho. Um observador da cultura estuda como as manifestações culturais se ligam aos padrões, gerando conflitos, harmonia, ambiguidades, paradoxos e contradições. Neste estudo, trataremos as manifestações do significado da avaliação para os servidores e estudantes da UFU.

\subsubsection{As três perspectivas}

Martin, Frost e O'Neill (2004) propõem três perspectivas nos estudos sobre cultura organizacional: integração, diferenciação e fragmentação. Os estudos relativos à integração são caracterizados pela consistência das interpretações culturais, pela organização voltada para o consenso e pela transparência. As empresas tem muitas manifestações culturais como: práticas formais e informais, histórias dos funcionários, rituais, jargões específicos, normas de conduta, entre outros.

Segundo Passos (2005) na perspectiva da integração existe elementos que são compartilhados por todos, de modo homogêneo e são balizadores das interpretações partilhadas por quase todos, algumas opostas aos objetivos organizacionais e outras convergentes. No artigo de Lanz e Tomei (2004), é mostrado isso quando a cultura da empresa estudada foi alinhada em torno da subcultura de finanças, gerando uma concordância cultural entre os funcionários, a qual refletiu no desempenho financeiro. Nesse caso, os elementos integradores estavam alinhados com os objetivos organizacionais.

$\mathrm{Na}$ diferenciação considera-se o consenso apenas dentro dos limites das subculturas existentes nas empresas. Entre as subculturas não existe esse consenso. Ao contrário dos estudos sobre integração, os estudos sobre diferenciação são mais sensíveis às influências do ambiente. Os estudos mostram que as subculturas de uma empresa refletem os grupos culturais existentes na própria sociedade (MARTIN; FROST; O'NEILL, 2004).

Por último, na perspectiva da fragmentação são encontrados valores os quais são compartilhados momentaneamente pelos membros dos grupos organizacionais diferentes. Conforme Passos $(2005$, p. 6) "é no terreno do conflito 
entre as perspectivas integradoras e diferenciadoras que o foco vai para a busca de elementos que revelem valores partilhados [...]". Este autor, em seu artigo, identificou como temas que são compartilhados por grupos distintos, os seguintes: espaço físico, condições de trabalho e elevado número de terceirizados.

O ambiente organizacional é heterogêneo e, por isso, por mais que as organizações tentem difundir uma cultura organizacional única e homogênea, elas não conseguirão. Cada pessoa traz para dentro da empresa sua história e isso contribui para que surjam outras culturas e a contracultura. $\mathrm{O}$ que as instituições precisam é gerenciar todas essas diversidades a seu favor. No próximo tópico será descrita a metodologia usada para a realização desta pesquisa.

\section{Aspectos Metodológicos}

Este estudo, quanto aos seus objetivos, é descritivo. Para este trabalho, optou-se pelo método de procedimento do estudo de caso. De acordo com Yin (1989), a preferência pelo uso deste método deve ser dada, quando do estudo de eventos contemporâneos, em situações nas quais os comportamentos relevantes não podem ser manipulados, sendo possível se fazer observações diretas e entrevistas sistemáticas.

O objeto de estudo desta pesquisa é composto de técnicos-administrativos da classe E com função gratificada, documentos da instituição, como os Relatórios e Projetos de Avaliação Institucional já realizadas, e do Ministério da Educação como, por exemplo, orientações sobre o SINAES. Os entrevistados foram escolhidos entre os servidores técnicos-administrativos da classe E com função gratificada, pois acreditava-se que eles seriam os líderes que permaneceriam na organização, apesar da alternância de poder que ocorre com as eleições nas universidades. Esse critério se deu porque, conforme Schein (2010), a liderança é um importante elemento influenciador da cultura.

Foram entrevistados 16 indivíduos selecionados por conveniência, a partir de uma listagem de todos os ocupantes de TAs da classe E com cargos de confiança na Universidade. Buscou-se, dessa forma, se obter uma homogeneidade em termos de cargos e níveis hierárquicos, conforme sugerido por Bauer e Aarts (2002). Foram seguidas as etapas de seleção dos entrevistados, busca da variedade em seus discursos e seleção novamente, para se ter certeza que as variações das falas foram minimizadas.

Foram coletados dados em dois períodos distintos: 2009 e 2013. Em 2009, no primeiro ano de realização das entrevistas, utilizou-se a base de servidores técnicos-administrativos referente a dezembro de 2008. Na época, a UFU 
possuía um total de 3.198 técnicos-administrativos, sendo que 697 eram da classe E (técnicos com no mínimo graduação) e entres esses havia 112 que ocupavam cargos de chefia. Já no ano de 2013, a referência do número de TAs foi de dezembro de 2012. Neste momento havia 3.215 servidores técnicos-administrativos, 797 eram concursados da classe E e destes 134 tinham função gratificada. Esta pesquisa focou-se apenas em um desses segmentos dos técnicos-administrativos que possuíam cargos de chefia e que sejam do nível de classificação E, conforme plano de carreira dos mesmos. Essa escolha se deu pelo entendimento de que os líderes influenciam a cultura organizacional (SCHEIN, 2010).

Em complemento às entrevistas, buscou-se dados de documentos da Instituição e do MEC com o objetivo de resgatar o histórico das avaliações institucionais que já ocorreram na Universidade. A primeira etapa deste trabalho se deu no ano de 2009 e os discursos foram coletados por meio de entrevista em profundidade Depois de feitas as entrevistas, elas foram transcritas e submetidas à técnica de análise de conteúdo para descobrir os significados mais citados. Em seguida, as respostas foram relacionadas entre si para que pudessem ser agrupadas segundo as três perspectivas de Martin (2002). As entrevistas juntamente com a análise documental, permitiram fazer uma relação entre o discurso da organização e a percepção de seus atores.

Na segunda etapa desta pesquisa, realizada em 2013, procurou-se novamente os mesmos entrevistados do ano de 2009 e foi seguido um roteiro de entrevista idêntico ao anterior. O objetivo era descobrir se após 3 anos se encontrariam significados diferentes para a autoavaliação institucional. Os discursos também foram transcritos, analisados e separados dentro das três perspectivas de Martin (2002). Após isso, relacionaram-se as falas dos entrevistados de ambos os anos com a finalidade de identificar mudanças nelas.

Como em toda pesquisa, nesta também se encontram algumas limitações. A primeira é que o pesquisador pode interferir nos resultados, não sendo totalmente imparcial. A avaliação institucional também foi feita com egressos, com a sociedade civil, docentes e discentes, porém este estudo não contempla estes segmentos, o que o limita a uma visão apenas interna e de um segmento da instituição. Por último, não foi possível fazer as entrevistas com alguns dos participantes de 2009, pois quatro deles tinham se aposentado ou estavam afastados. Apesar dessas ausências a qualidade e os objetivos da pesquisa não foram afetados, pois a partir da décima terceira entrevista não se observou novas percepções e por isso, decidiu-se por encerrar a coleta de dados seguindo o critério de saturação dos dados coletados. 


\section{Resultados}

\subsection{Histórico das avaliações institucionais}

A primeira avaliação institucional de que se tem conhecimento na Universidade Federal de Uberlândia foi o Programa de Avaliação da Reforma Universitária (PARU) realizado em 1991 e no primeiro semestre de 1992. Apesar do Programa de Avaliação Institucional das Universidades Brasileiras - PAIUB ter surgido em 1993, a avaliação feita pela UFU ainda se encontrava nos moldes do programa de avaliação anterior, o PARU.

Seguindo o modelo da época, que privilegiava os dados quantitativos das Instituições de Ensino Superior, a UFU criou sua sistemática de avaliação em 1991. A primeira ação tomada pelo reitor da época foi a criação de uma comissão para conduzir os trabalhos. O princípio dessa comissão era "a participação efetiva e o diálogo aberto e franco entre todos os envolvidos, de forma que simultaneamente avaliador e avaliado se inter-relacionem num processo de desenvolvimento contínuo e emancipador" (UNIVERSIDADE, 1991, p. 1).

$\mathrm{Na}$ avaliação de 1991 foi feita em três etapas. A primeira foi a de planejamento, construção e aplicação dos instrumentos de coleta de dados. $\mathrm{Na}$ segunda etapa foi criado o Relatório de Atividades dos Departamentos que captou os dados históricos dos departamentos, de acordo com a classificação já estabelecida no Elenco de Indicadores de Avaliação. A última etapa foi a apresentação do relatório final. Foi feito um documento com os resultados alcançados pelos departamentos e este foi entregue à administração superior da UFU.

Após essa avaliação realizada em 1991 e finalizada em 1992, não se tem histórico de outra, até o ano de 2006. Um dos motivos para isso pode ser o fato de que, em 1993, o novo programa de avaliação do MEC - PAIUB - era com adesão voluntária das IES. Então, se tem um período de mais de 10 anos sem uma avaliação formal da Universidade Federal de Uberlândia.

Em 2002, para atender à Lei n ${ }^{0} 10.172 / 2001$, que institui o Plano Nacional de Educação (PNE), a Universidade Federal de Uberlândia, ao aprovar o Regimento Interno do Conselho Universitário por meio da Resolução n ${ }^{\circ}$ 10/2002, cria a CPAI - Comissão Permanente de Avaliação Institucional (UNIVERSIDADE, 2005). Com a criação dos SINAES deu-se inicio ao primeiro ciclo de avaliação institucional na Universidade Federal de Uberlândia. Essa avaliação era entendida como um processo contínuo por meio do qual uma instituição constrói conhecimento sobre sua própria realidade e buscou compreender os significados do conjunto de suas atividades e segmentos da UFU, visando a 
melhoria da qualidade educativa e a maior relevância social. Este processo foi conduzido pela Comissão Própria de Avaliação (UNIVERSIDADE, 2012).

As competências da Comissão Própria de Avaliação contradizem o foco da administração pública gerencial que se concentra nos resultados e na satisfação do cidadão (BRESSER, 2006). Fica claro que o cerne da CPA continua recaindo sobre os processos e não nos resultados que serão gerados por meio da Autoavaliação Institucional.

No Projeto de Avaliação Institucional 2001-2005, elaborado pela CPA, definiram-se como objetivos centrais (UNIVERSIDADE, 2005, p. 18):

implantar, na Universidade Federal de Uberlândia, um processo contínuo de autoavaliação que possibilite dar a conhecer suas potencialidades e dificuldades, visando a melhoria da qualidade no desenvolvimento do ensino, da pesquisa e da extensão e gestão;

promover e difundir uma cultura de avaliação permanente que permita planejar e redirecionar as ações da UFU, no que diz respeito às atividades de ensino, pesquisa, extensão e gestão da Universidade;

fornecer, por meio dos resultados da autoavaliação, caminhos e propostas para a construção coletiva e revisão permanente do Plano de Desenvolvimento Institucional - PDI e Plano Pedagógico Institucional - PPI;

produzir conhecimentos sobre a atual situação da UFU, nas dimensões de ensino, pesquisa, extensão e gestão;

analisar a eficiência, a eficácia, a efetividade e a relevância social e científica dos programas e projetos institucionais de ensino, pesquisa, extensão e gestão;

desencadear um processo de autoavaliação coletivo, estimulando a inter-relação entre todos os atores envolvidos (docentes, discentes, técnicos-administrativos, egressos e entorno social), rumo ao constante aprimoramento do desempenho institucional.

Os objetivos elencados acima se aproximam de uma tentativa de implantação da administração pública gerencial, pois prioriza a melhoria dos serviços prestados ao cidadão, ou seja, os resultados obtidos com a Avaliação deverão ser utilizados para tal finalidade e não, simplesmente, para cumprir uma determinação do Governo. Eles também vão ao encontro de um dos critérios do SINAES, a prática social com objetivos educativos, porque deixa claro a tentativa de se implantar uma cultura de avaliação, de participação de todos num processo coletivo e, como meta maior, elevação da qualidade do ensino (INEP, 2009). 
Os questionários elaborados pela CPA e aplicados no ano de 2006 procuraram avaliar as 10 dimensões definidas na legislação sobre avaliação de institucional. Nunes (2006) afirma em seu estudo que as Instituições de Ensino Superior formam interligações internas entre seus diversos segmentos e setores. As dimensões propostas pelo MEC formam a grande rede que une as IES no objetivo comum indicado pelo SINAES que é a melhoria da qualidade e regulação do Estado nas organizações.

No ano de 2009, se iniciou um novo ciclo avaliativo 2009-2010 composto por duas etapas. A primeira se preocupou com os aspectos quantitativos da Autoavaliação, acompanhando a revisão do PIDE (Plano Institucional de Desenvolvimento e Expansão) e coletando dados da instituição. A segunda parte do trabalho se deu no ano de 2010 onde se interpretou os dados coletados na primeira fase e, por meio de questionários eletrônicos, buscaram dados qualitativos da Universidade. A tabela 01 mostra os percentuais de participação (UNIVERSIDADE, 2010). Embora tenha havido um crescimento na participação, a Autoavaliação Institucional de 2009-2010 não abrangeu todos os segmentos como a avaliação de 2006, mesmo sendo essa uma exigência do MEC.

\section{Tabela 1 - Universo da pesquisa para a avaliação institucional}

\begin{tabular}{|c|c|c|c|c|}
\cline { 2 - 5 } \multicolumn{1}{c|}{} & Número Total & Amostra Estatistica & $\begin{array}{c}\text { Número de } \\
\text { Participantes }\end{array}$ & $\%$ Participação \\
\hline Docentes & 1.521 & 129 & 622 & $40,1 \%$ \\
\hline Discentes de Graduação & 15.150 & 139 & 2.872 & $19,0 \%$ \\
\hline $\begin{array}{c}\text { Técnicos- } \\
\text { administrativos }\end{array}$ & 1.555 & 133 & 1.175 & $75,6 \%$ \\
\hline
\end{tabular}

Fonte: UNIVERSIDADE - Comissão Própria de Avaliação, 2010.

Em 2011 se começou um novo processo de Autoavaliação Institucional 2011-2012 e, após 6 anos do término do primeiro ciclo avaliativo 2001-2005, se tem, novamente, a aplicação dos questionários para todos os segmentos sugeridos pelo MEC: docentes, discentes de graduação e pós-graduação, técnicos-administrativos, egressos e sociedade civil. Em 2012 aconteceu o ciclo avaliativo mais recente que abordou, assim como em 2010, apenas os segmentos internos da Universidade, acrescentando os funcionários das fundações e os discentes dos cursos à distância. 
Cada um dos ciclos avaliativos citados nos parágrafos anteriores pode, de acordo com momento institucional no qual foram feitos, contribuir para a consolidação de um significado para uma cultura de avaliação dentro da Universidade Federal de Uberlândia. Porém, não se pode concluir, por meio da análise documental feita isoladamente, que isso realmente aconteceu. E mesmo a Comissão Própria de Avaliação afirmando em seus relatórios que essa cultura já é inerente na UFU, isso não é uma realidade.

É possível pensar que devido aos lapsos temporais onde a instituição ficou sem fazer a Avaliação Institucional: de 1993 a 2001 e de 2006 a 2010, e à baixa, mesmo que crescente, participação dos segmentos internos da Universidade. No ano de 2011, em uma universidade com aproximadamente 20.000 discentes, apenas $22 \%$ responderam aos questionários. Essas lacunas contradizem um dos princípios do SINAES que é o da continuidade, o qual é necessário para dar significado à Avaliação Institucional e se ter uma cultura avaliativa.

Polidori, Fonseca e Larrosa (2007, p. 5) relatam em seu artigo que para as avaliações serem participativas, os envolvidos não podem ser meros geradores de informações. Eles devem ser envolvidos durante todo processo. A partir do momento que se começa a enxergar os segmentos internos como parte do todo, cumpre-se os objetivos da avaliação institucional e é possível "evidenciar o que é preciso mudar e o que é preciso fortalecer e ampliar para a obtenção do sucesso relacionado à qualidade da educação superior". Os autores apontam como uma solução para este problema a sensibilização da comunidade universitária, despertando o sentimento de pertencimento ao passarem pelo processo avaliativo.

O Governo Federal ao exigir dos órgãos que administra uma avaliação, tenta se aproximar da new public management. Nikos (2001), afirma em seu trabalho que, devido às cobranças dos cidadãos (clientes) dos serviços públicos, é necessário inserir na administração pública alguns conceitos relacionados às empresas privadas, como avaliação, medição, produtividade e qualidade. Para ele, os cidadãos passam a ser agentes atuantes que podem definir algumas decisões. Por isso, na Autoavaliação Institucional, não se pode deixar de ir até a sociedade civil e deixar que ela avalie a Universidade e, durante os seis anos de Avaliação na UFU, isso foi feito somente duas vezes o que pode levar a um desvio do objetivo do processo que é o de melhoria na prestação dos serviços público.

\subsection{A posição daqueles que formam opinião: os gestores}

A partir das entrevistas realizadas nos anos de 2009 e 2013, organizaram-se os discursos para identificar o significado da Avaliação Institucional em 
cada um deles. Com isso, foi possível separar os indivíduos em dois grupos, os que atribuíram algum significado para a avaliação institucional e aqueles que não viam nenhum significado. Assim, separaram-se dois temas principais: significado e sem significado. O quadro 1 a seguir, mostra os significados encontrados nos dois anos:

\section{Quadro 1 - Significados encontrados}

\begin{tabular}{|c|c|c|}
\hline Entrevistados & Significados em 2009 & Significados em 2013 \\
\hline 1 & Conhecer a Instituição & Processo importante para reavaliar \\
\hline 2 & Rumos da Instituição & $\begin{array}{l}\text { Saber como está a Instituição e direcionar a } \\
\text { tomada de decisões }\end{array}$ \\
\hline 3 & Saber o posicionamento da Instituição & Direcionar as atividades \\
\hline 4 & Sem significado & Positivo para ver o andamento e melhorar \\
\hline 5 & Sem significado & Não teve entrevista \\
\hline 6 & Sem significado & Importante \\
\hline 7 & $\begin{array}{l}\text { Utilização dos resultados para ações concretas } \\
\text { de melhoria }\end{array}$ & Não utilizam resultados para ações práticas \\
\hline 8 & $\begin{array}{l}\text { Não houve desdobramentos dos resultados da } \\
\text { avaliação }\end{array}$ & $\begin{array}{l}\text { Importante, porém a UFU só cumpre uma } \\
\text { determinação. }\end{array}$ \\
\hline 9 & Sem ações práticas com os resultados & Definir rumos e melhorar \\
\hline 10 & Sem significado & Não teve entrevista \\
\hline 11 & Mostrar as deficiências da Instituição & Não teve entrevista \\
\hline 12 & Fazer um projeto para a Instituição & $\begin{array}{l}\text { Divulgação da utilização dos resultados e } \\
\text { melhorias obtidas }\end{array}$ \\
\hline 13 & Sem significado & Fazer melhorias \\
\hline 14 & $\begin{array}{l}\text { Estimulo para melhoria e oportunidade de } \\
\text { mostrar o que è feito. }\end{array}$ & Nortear as ações e corrigir os rumos \\
\hline 15 & Oportunidade de crescimento e melhoria & $\begin{array}{l}\text { Oportunidade de melhorias, mas não aproveitam } \\
\text { os resultados para isso. }\end{array}$ \\
\hline 16 & Importante para melhorias & Não teve entrevista \\
\hline 17 & Não teve entrevistado & $\begin{array}{l}\text { Oportunidade de o servidor conhecer o setor onde } \\
\text { trabalha. }\end{array}$ \\
\hline
\end{tabular}

Fonte: Resultados da pesquisa

A partir da análise comparativa entre as duas datas, nota-se que em 2009, cinco dos entrevistados não atribuíram nenhum significado à Avaliação Institucional. Já em 2013, todos os respondentes enxergavam algum significado, mesmo não tendo respondido ao questionário da avaliação.

No ano de 2013 o número de indivíduos que responderam ao questionário ainda é menor do que os servidores que não participaram. Sendo a amostra deste estudo composta apenas TAs que possuem cargos de chefia são os responsáveis pela disseminação dos pressupostos de uma cultura, conforme Schein (2010), se pode inferir que o fato da maioria ainda não participar da avaliação, mostra uma "cultura de avaliação" não evidenciada na organização. 
Nas entrevistas realizadas em 2009, foram encontrados dois temas principais: significado, indivíduos que atribuíram significado à avaliação, e sem significado. Dentro do primeiro, significado, se encontrou cinco subtemas apresentados no quadro 2, juntamente com algumas das falas que os caracterizam:

\section{Quadro 2 - Discurso dos entrevistados - Significado}

\begin{tabular}{|l|l|}
\hline Subtemas & Discursos \\
\hline Conhecer a Instituição & $\begin{array}{l}\text { "[..] eu acho que essa avaliação é importante, no sentido de ele } \\
\text { estar conhecendo, né, a... a questão do que está ocorrendo, das }\end{array}$ \\
\hline \hline & $\begin{array}{l}\text { necessidades que está tendo aqui e para a instituição eu acho } \\
\text { importante essa troca [...]" }\end{array}$ \\
\hline Rumos da Instituição & $\begin{array}{l}\text { "Para a universidade em si ela foi muito boa porque avaliava como } \\
\text { estava a instituição, o quê que ela era, como ia ficar e aonde iria } \\
\text { chegar futuramente." }\end{array}$ \\
\hline $\begin{array}{l}\text { Posição da Instituição } \\
\text { (ranking) }\end{array}$ & $\begin{array}{l}\text { "Ainda não recebemos essa última avaliação, ainda não temos nada, } \\
\text { resposta nenhuma, por enquanto. Mas, eu, to aguardando para ver, } \\
\text { que classificação a gente vai pegar." }\end{array}$ \\
\hline $\begin{array}{l}\text { Ações práticas com } \\
\text { resultados encontrados }\end{array}$ & $\begin{array}{l}\text { "É... e foi, assim, um trabalho grande que a universidade fez, mas no } \\
\text { final de tudo eu creio que os resultados não foram utilizados. Eu falo } \\
\text { pela própria Pró-Reitoria X, que eu imprimi a parte que focava a Pró- } \\
\text { Reitoria X, passei pra pessoa mais indicada pra dar atenção naquilo } \\
\text { ali, pra dar resposta pro que tinha levantado e nada foi feito. Então, } \\
\text { sinceramente, assim, eu não sei se, na prática mesmo, se essa } \\
\text { avaliação pra nós aqui teve algum resultado não." }\end{array}$ \\
\hline "Um estímulo para gente aperfeiçoar o que nós já fazemos, mas \\
também para mostrar aquilo que já vem sendo feito."
\end{tabular}

Fonte: Resultados da pesquisa

No segundo tema, sem significado, se encontrou, também, quatro subtemas, apresentados a seguir no quadro 3:

\section{Quadro 3 - Discurso dos entrevistados - Sem significado}

\begin{tabular}{|l|l|}
\hline Subtemas & Discursos \\
\hline Confundiu com a avaliação de desempenho & $\begin{array}{l}\text { "De desempenho que teve e que nós fizemos de todos os funcionários pra eles } \\
\text { progressão de carreira e isso foi uma das avaliações." }\end{array}$ \\
\hline Não se lembra & "Não me recordo. Não me lembro." \\
\hline Sem importância & $\begin{array}{l}\text { "Nenhum." } \\
\text { "Não cheguei a responder não." } \\
\text { "Eu acredito que eu realmente não tenha me interessado." }\end{array}$ \\
\hline
\end{tabular}

Fonte: Resultados da pesquisa

É importante ressaltar que foi identificado nos discursos dos entrevistados, falas que contradizem aos objetivos apresentados no documento: A Autoavaliação Institucional na Universidade Federal de Uberlândia (CPA, 2005). O objetivo geral proposto nesse relatório é que a avaliação institucional identificasse na 
universidade as condições de ensino, pesquisa e extensão, as potencialidades e fragilidades, com vistas à melhoria da sua qualidade por meio do redirecionamento do planejamento e das ações das Unidades Acadêmicas, Administrativas e da gestão da Universidade. Porém, alguns discursos revelaram que não foram traçadas metas e ações, e nem feito um planejamento a partir dos resultados da avaliação institucional, como exemplificado na fala do entrevistado 8:

Eu acho que não foi muito abrangente, assim, acho que não teve muito desdobramento. E nem naquele momento mesmo, parecia muito objetivo isso. De onde queriam chegar com essa avaliação. Então, ficou um pouco parece meio solto. Mesmo depois de concluído tudo. Não teve, assim, um desdobramento, uma definição de atitudes, com base nessa avaliação, no sentido de mudar a Universidade, melhorar ou alguma coisa assim.

Isso explica o fato de alguns servidores não verem significado na avaliação, pois os resultados não foram divulgados corretamente e nem utilizados para traçar as ações futuras para Universidade. Vai ao encontro, também, dos que os autores Andriola e Souza (2010) discutem em seu artigo sobre a relação entre ausência de uma cultura avaliativa e o fato de que, para isso, os participantes devem conhecer os objetivos e a importância do processo avaliativo no qual estão inseridos.

Alguns dos entrevistados, ao serem questionados sobre a avaliação institucional, acharam que era a avaliação de desempenho realizada para a progressão na carreira. A partir de tais evidências é possível pensar que estes não conhecem o conceito de avaliação institucional e que na época na qual ela foi realizada, não ficaram sabendo do processo que estava acontecendo no âmbito da Universidade. Um dos entrevistados disse que os técnicos-administrativos responderam ao questionário como se fosse o da avaliação de desempenho e, que depois, ligavam no setor responsável por tal avaliação para saber quando sairia a progressão na carreira e aumento salarial. Isso mostra, ainda, que existe um grupo de servidores que são alheios ao cotidiano da instituição e só se envolvem em questões onde possam ter algum beneficio pessoal. Outro fato que mostra isso é que $21 \%$ dos entrevistados não se lembram dessa avaliação e nem que ela tenha ocorrido.

Dos 16 entrevistados em 2009, quatro não veem nenhum significado na avaliação institucional. Entre eles, dois, não responderam o roteiro da entrevista e se lembram do processo avaliativo, porém não tiveram interesse em participar. Esse fato, também mostra a falta de interesse no cotidiano organizacional, de envolvimento com as questões internas da universidade e inexistência de uma 
cultura de avaliação. Polidori, Fonseca e Larrosa (2007, p. 11) apontam em seu estudo alguns fatores que podem explicar a não participação no processo. São eles: necessidade de haver uma maior divulgação; de proporcionar uma maior praticidade no preenchimento dos formulários; de que ocorra um retorno relacionado ao desenvolvimento do processo avaliativo; da manifestação do desejo de participação no processo na sua totalidade e não somente numa parte dele e, alguma dificuldade quanto ao formato do formulário.

Na UFU pode-se identificar como falhas nas Auto-avaliações Institucionais a falta de divulgação, como relatado pelo entrevistado 10: "Pesquisadora: E por que você não participou em 2006? Entrevistada: Não tenho lembrança se foi divulgado. Você lembra a época que foi?", e a perspectiva de se ter um retorno a partir do que foi coletado com o processo avaliativo:

Bom, eu poderia dizer um resultado, que se alguém divulgasse o resultado, se houve melhoria, se houve... se a Universidade alcançou o que ela desejava. Se divulgasse um planejamento. Eu na realidade não sei. Eu sei que teve essa avaliação, mas não sei os resultados, nem os indicadores, no caso ai, dos anos anteriores, se houve melhora, se houve crescimento, se não teve isso, eu acho que falta divulgar para a Universidade.

No ano de 2013 teve-se um total de 13 entrevistados e encontrou-se apenas um tema principal: com significado. Foram evidenciados cinco subtemas os quais estão no quadro 5 a seguir, juntamente com partes dos discursos.

\section{Quadro 4 - Discurso dos entrevistados - Significado}

\begin{tabular}{|l|l|}
\hline Subtemas & Discursos \\
\hline Importante para reavaliação & $\begin{array}{l}\text { "[...]eu vi que a instituição estava fazendo novamente, no momento que eu } \\
\text { recebi o e-mail eu achei que era interessante isso para a instituição, para ela } \\
\text { poder reavaliar, porque ela já tinha passado por outros processos." }\end{array}$ \\
\hline $\begin{array}{l}\text { Conhecer Instituição para nortear as } \\
\text { atividades }\end{array}$ & $\begin{array}{l}\text { "[..] o que tem na avaliação institucional é como está a Instituição. Então, em } \\
\text { cima disso é que a gente vai fazer." } \\
\text { "Olha, eu acho que, fazendo uma análise bem ampla, ela pode direcionar } \\
\text { muitas atividades dentro da Universidade." }\end{array}$ \\
\hline Melhorias & $\begin{array}{l}\text { "[...], na medida em que alguma área tem uma avaliação de que algo não está } \\
\text { caminhando bem, a possibilidade de detectar essa falha é maior" } \\
\text { "[...] e com base nisso, mover na parte de planejamento, no intuito de melhora, } \\
\text { de buscar melhoria." }\end{array}$ \\
\hline Importante & $\begin{array}{l}\text { "Tem, é importante, se a gente não faz até está errado." } \\
\text { "Acho muito importante a avaliação, mas infelizmente no serviço público essas } \\
\text { avaliações acabam sendo mais é pra cumprir determinação do Ministério [...]". }\end{array}$ \\
\hline Ações práticas com resultados encontrados & $\begin{array}{l}\text { "Eu acredito nisso desde que realmente aquilo seja levado a sério, porque eu } \\
\text { sei que é uma avaliação muito rica, desde o principio sempre foi uma avaliação } \\
\text { muito rica. Agora o que está sendo feito com esses resultados é que eu não } \\
\text { sei." }\end{array}$ \\
\hline
\end{tabular}

Fonte: Resultado da pesquisa 
Ao se comparar os significados encontrados nos diferentes anos, se tem somente dois subtemas que aparecem em ambos, sendo eles "melhorias" e "ações práticas com os resultados encontrados". O SINAES recomenda que a Autoavaliação Institucional sirva para a Universidade "conhecer as fortalezas e os problemas da instituição, tratar da adequação de seu trabalho com respeito às demandas sociais, as clássicas e as novas, identificar os graus de envolvimento e os compromissos de seus professores, estudantes e servidores tendo em vista as prioridades institucionais básicas" (INEP, 2009, p. 105). Tal concepção vai ao encontro dos discursos dos técnicos-administrativos, pois eles creem que a Avaliação possa ser algo maior, porém não veem isso sendo feito na prática ao se utilizar os resultados encontrados como oportunidade de melhorias.

O entrevistado 7 relata que respondeu aos questionários de todos os anos, com exceção de 2012. Justifica tal decisão pelo fato de nunca ter visto como a UFU está utilizando as informações conseguidas por meio do processo avaliativo. Já o entrevistado 12 não participou somente em 2012, mas, mesmo assim, atribuiu significado ao processo de 2006 e esperava que por meio dele fosse criado um projeto de futuro para a Universidade. Quando questionado sobre o de 2012, ele diz não saber descrever qual foi o resultado: "Bom, eu não sei... eu não sei te responder porque... eu não sei... eu não vi... eu não acompanhei assim, os resultados, né, mas eu creio que... dependendo da, do banco de dados dessas pessoas, realmente deveria ter apresentado um resultado que poderia ser projetado para fazer uma meta ou uma... é... um projeto da universidade, em tudo, né."

Os relatos vão ao encontro do que os autores Venturini et al. (2010) encontraram em sua pesquisa com os docentes da Universidade Federal de Santa Maria. Os sujeitos da pesquisa ao serem indagados sobre fatores que interferem na gestão e dificultam o processo de avaliação, responderam quanto a descrença na utilização dos resultados.

Com isso, percebe-se que, mesmo depois de seis anos da primeira Avaliação Institucional, os técnicos-administrativos continuam sem enxergar direcionamentos concretos com os dados obtidos por meio dos questionários aplicados e de suas análises. No relatório do ano de 2012, a CPA afirma que uma ação desencadeada, por causa do processo avaliativo do ano de 2006, foi a criação do PIDE da UFU. Porém, como os entrevistados não relataram tal fato, conclui-se que eles não veem isso como uma ação prática com os resultados obtidos.

Os significados conhecer a Instituição, rumos da Instituição, ações práticas com os resultados encontrados e melhorias, evidenciados nos discursos de 2009, e os de 2013, conhecer a Instituição para nortear as atividades, vão ao encontro do estudo da autora Brito (2008, p. 841 - 842) que ressalta: 
A avaliação, quando concebida como um processo dinâmico, pode ser usada como referencial para que as Instituições de Educação Superior disponham de evidências empíricas não apenas de suas debilidades, mas também de suas potencialidades e de suas realizações. Conhecendo e dando a conhecer os elementos que integram e interagem em cada IES, é possível transformá-la em direção às metas almejadas, organizando a instituição de modo que esta atue e forme profissionais engajados e comprometidos com uma sociedade em constante mudança.

Conforme objetivo proposto nesse trabalho, os subtemas encontrados foram agrupados conforme as três perspectivas de Martin (2002). O quadro seis, a seguir, mostra como os subtemas das entrevistas feitas em 2009 foram dispostos dentro das perspectivas:

\section{Quadro 5 - Subtemas da avaliação institucional separados de acordo com as três perspectivas -2009}

\begin{tabular}{|l|l|l|}
\hline \multirow{2}{*}{ Integração } & Diferenciação & Fragmentação \\
\hline \multirow{4}{*}{ Não identificada } & Conhecer a Instituição & Posição da Instituição (ranking) \\
\cline { 2 - 3 } & Rumos a Instituiç̧ão & \\
\cline { 2 - 3 } & Ações práticas com os resultados obtidos & \\
\cline { 2 - 3 } & Melhorias & \\
\hline
\end{tabular}

Fonte: Resultado da pesquisa

De acordo com as informações do quadro 6, nenhum subtema é compartilhado pelos entrevistados, ou seja, não se identificou integração entre os discursos. Também não há integração entre os temas principais, significado e sem significado. Como as entrevistas foram realizadas com cargos de chefia, então, é possível pensar que as chefias não compartilham conjuntamente nenhum significado naquilo que se refere à avaliação institucional, nem entre eles e nem com seus subordinados, mostrando, assim, que, para as questões relacionadas à avaliação institucional, eles não cumprem seus papéis de líderes, disseminando as ações internas da instituição e servindo como referência a elementos da cultura organizacional, particularmente naquilo que se refere à ideia de avaliação institucional. Tais constatações vão de encontro daquilo que a literatura de cultura aponta para a relação entre cultura organizacional e liderança (FREITAS, 1991; MARTIN, 2002). 
Também se pode inferir a partir do quadro 6, que a própria UFU não buscou organizar táticas ou controles para que o processo de Avaliação Institucional envolvesse seus servidores e direcioná-los para um objetivo comum. A maioria dos subtemas enquadram-se na perspectiva da diferenciação, ou seja, são compartilhados, porém não por todos os técnicos-administrativos, somente por pequenos grupos distintos.

O significado caracterizado como fragmentação, não compartilhado por todos, recai no que as autoras Leite (2008) e Brito (2008) destacam em seus trabalhos, o fato do SINAES tornar-se um no ranking por causa da criação do ENADE. Elas contam que em 2008 o MEC lançou um novo posicionamento da IES, contrariando o que a própria lei do SINAES propõe.

Diferentemente de 2009, nas entrevistas realizadas em 2013 já se identificou integração entre os discursos, pois todos os entrevistados atribuem significado à Avaliação Institucional. Então, não se tem mais dois temas principais e, sim, um único que integra todas as falas. O quadro 7 a seguir mostra como os subtemas foram agrupados na teoria de Martin (2002).

\section{Quadro 6 - Subtemas da avaliação institucional separados de acordo com as três perspectivas $-\mathbf{2 0 1 3}$}

\begin{tabular}{|l|l|l|}
\hline Integração & Diferenciação & Fragmentação \\
\hline Significado & Conhecer a Instituiç̧ão para nortear as atividades & Importante para reavaliar \\
\hline Significado & Importante & \\
\hline Significado & Ações práticas com os resultados obtidos & \\
\hline Significado & Melhorias & \\
\hline
\end{tabular}

Fonte: Resultado da pesquisa

Dois dos subtemas de 2009 continuam sendo evidenciados em 2013: ações práticas com os resultados obtidos e melhorias. A partir do primeiro conclui-se que esse aspecto da Avaliação continua não sendo trabalhado pela UFU e, de acordo com o segundo, os servidores persistem na ideia de que a avaliação deve gerar melhorias na Universidade. O subtema conhecer a Instituição para nortear as atividades, mesmo sendo parecido com o conhecer a Instituição de 2009, evidencia outro aspecto de direcionamento das ações e políticas e, não, somente de saber como é a organização. 


\section{Considerações finais}

A Avaliação Institucional realizada pelas IES deve ser um instrumento capaz de fazer uma avaliação interna das organizações de forma que elas consigam compreender o ambiente em que estão inseridas e seus segmentos para atendê-los conforme necessidades distintas. Ela deve permitir identificar os rumos a serem seguidos, entender a razão de suas fragilidades e enxergar as ações positivas para dar continuidade a elas. Além disso, Ela deve ser um processo independente para que consiga atingir seu objetivo de continuidade das ações e de implantação de um significado para uma cultura de avaliação.

O presente trabalho procurou analisar os significados atribuídos à avaliação institucional pelos técnicos-administrativos da classe E com função gratificada da Universidade Federal de Uberlândia. Por meio das entrevistas realizadas nos anos de 2009 e 2013, foram identificados tais significados de maneira a analisá-los posteriormente. A partir do histórico das avaliações evidenciou-se as lacunas entre as avaliações realizadas pela Universidade. Esses intervalos são um dos aspectos que explicam a falta de evidenciação de um significado para uma cultura de avaliação na UFU, pois mostra a descontinuidade do processo. (UNIVERSIDADE, 2009; 2013)

Ao identificar os significados atribuídos pelos técnicos-administrativos, de nível E com função gratificada da Universidade Federal de Uberlândia à avaliação institucional notou-se que maioria ainda não responde ao questionário da Autoavaliação Institucional. Nos discursos fica evidenciado que eles desconhecem os resultados práticos dela, mesmo que eles existam. Isso contribui para que a Avaliação caia em descrédito e se torne um processo automático e sem o envolvimento dos servidores.

Após agrupar os significados da avaliação institucional conforme a ideia de integração, fragmentação e diferenciação foi possível identificar aspectos presentes no cotidiano da Instituição como, por exemplo, o desinteresse por processos de avaliação, desconhecimento sobre a Autoavaliação Institucional, a baixa participação dos segmentos, que servirão para os gestores conduzirem as próximas as Avaliações Institucionais, a fim de se implantar uma avaliação, como proposto pelo SINAES. Também verificou-se que, apesar de se ter muitas melhorias ainda por serem feitas como, conseguir uma participação efetiva dos discentes da pós-graduação, nas entrevistas do ano de 2013 todos os entrevistados já conheciam a Autoavaliação Institucional e conseguiam atribuir significado a ela como, por exemplo, "importante para reavaliação". Não houve casos de não se lembrar ou confundir com a avaliação de desempenho ou não identificar um significado. 
Dessa forma, conclui-se que na UFU não há cultura de avaliação por que, segundo a perspectiva de Martin deveria haver mais elementos na categoria Integração. Ao contrário, houve diversos outros elementos, como as lacunas temporais, que contribuíram para a geração de problemas na avaliação.

O problema da inexistência de um histórico mais consistente de avaliação na Universidade Federal de Uberlândia, identificado com esta pesquisa, poderá ser amenizado a partir do momento em que a Instituição: 1) não tiver mais lacunas entre suas avaliações; 2) evidenciar os aspectos qualitativos da Avaliação Institucional; e 3) mostrar para a comunidade universitária que as análises feitas com os resultados da avaliação geram políticas, direcionamentos e melhorias dentro da Universidade. A UFU deve fazer uma análise interna de modo a identificar as razões destes problemas e, a partir disso, traçar planos utilizando o trabalho desencadeado pela Autoavaliação Institucional.

Compartilha-se do pensamento dos autores citados neste estudo, de que, a cultura organizacional é uma das formas de explicar e entender aquilo que é relevante em uma organização. Assim, torna-se possível apreender o cotidiano das organizações e propor ações que vão ao encontro de expectativas, a partir das deliberações conjuntas. Além disso, também se buscou entender de que maneira os ocupantes de cargos de chefia estão alinhados com os gestores e com o próprio Governo. Neste sentido, acredita-se que, a partir da análise do discurso, e da sua relação com as três perspectivas de Martin (2002), é possível analisar processos avaliativos e verificar quais devem ser as ações corretivas no sentido de alcançar o objetivo principal: a melhoria do serviço público.

O fato de que, no ano de 2009, quatro dos entrevistados não atribuíram significado à avaliação revela uma dissonância entre aquilo que as diretrizes governamentais pretendem e o que é realmente implementado. Os desafios avaliação institucional podem ser evidenciados a partir da falta de domínio conceitual e metodológico, da descontinuidade das avaliações e da falta de clareza quanto à divulgação dos resultados.

Por meio das entrevistas, verificou-se que o processo avaliativo ainda é visto como algo feito somente para cumprir determinações, sem se fazer uma reflexão sobre o assunto. Responde-se a um questionário quase que de forma automática. Mesmo os indivíduos que atribuem significado à avaliação nunca a examinem como algo maior. Eles questionam a falta de resultados práticos, mas não fazem as suas próprias autoavaliações, dentro de seus setores de trabalho. Não se encontrou na literatura analisada, trabalhos que estudem como cada pessoa melhora ou modifica seu própria trabalho, a partir do que é apresentado na Autoavaliação Institucional. 


\section{Referências}

ANDRIOLA, Wagner Bandeira; SOUZA, Laura Alves de. Representações sociais dos gestores e dos técnicos das unidades acadêmicas da Universidade Federal do Ceará (UFC) acerca da autoavaliação institucional. Avaliação, Campinas; Sorocaba, v. 15, n. 2, p. 45-72, jul. 2010.

BAUER, Martin W.; AARTS, Bas. A construção do corpus: um princípio para a coleta de dados qualitativos. In: BAUER, M.; G GASKELL, G. (Org.). Pesquisa qualitativa com texto, imagem e som. Petrópolis: Vozes, 2002. p. 39-63.

BRASIL. Plano Nacional de Educação (PNE). Lei 10.172/2001. Brasília: Congresso Nacional, 2001.

BRESSER, Luiz Carlos Pereira. Gestão do setor público: estratégia e estrutura para um novo Estado. In: REFORMA do Estado e Administração Pública Gerencial. Rio de Janeiro: Ed. FGV, 2006. p. 21-38.

BRITO, M. R. F. O SINAES e o ENADE: da concepção à implantação. Avaliação, Campinas, Sorocaba, SP, v. 13, n. 3, p. 841-850, nov. 2008.

COLAUTO, Romualdo Douglas; BEUREN, Ilse Maria. Proposta para avaliação da gestão do conhecimento em entidade filantrópica: o caso de uma organização hospitalar. Revista de Administração Contemporânea, São Paulo, v. 7, n. 4, out./dez., p.163-185, 2003.

DI PIETRO, Maria Sylvia Zanella. Direito administrativo. 18. ed. São Paulo: Atlas, 2005.

DIAS SOBRINHO, José. Avaliação institucional: marcos teóricos e campos políticos. Avaliação, Campinas, v. 1, n. 1, jul. 1996.

FREITAS, Maria Ester. Cultura Organizacional: grandes temas em debate. Revista de Administração de Empresas, São Paulo, v. 31, n. 3, p. 73-82, jul./set. 1991.

HOLANDA, Antônio Nilson Craveiro. Avaliação de políticas públicas: conceitos básicos, o caso do ProInfo e a experiência brasileira. In: CONGRESSO INTERNACIONAL SOBRE LA REFORMA DEL ESTADO Y LA ADMINISTRACION PUBLICA, 8., 2002, Panamá. 
INEP - INSTITUTO NACIONAL DE ESTUDOS E PESQUISAS EDUCACIONAIS ANÍSIO TEIXEIRA. Sistema Nacional de Avaliação da Educação Superior. 2.ed. Brasília, 2004. Disponível em < http://www.inep. gov.br/superior/sinaes/>. Acesso em: 12 dez. 2007.

INEP - INSTITUTO NACIONAL DE ESTUDOS E PESQUISAS EDUCACIONAIS ANÍSIO TEIXEIRA. Sistema Nacional de Avaliação da Educação Superior. 5.ed. Brasília, 2009. Disponível em < http://www.inep. gov.br/superior/sinaes/>. Acesso em: 2 ago. 2012.

LANZ, Luciano Quinto; TOMEI, Patricia Amélia. Mudança organizacional e desempenho financeiro: o papel da concordância cultural. In: ENCONTRO NACIONAL DA ASSOCIAÇÃO NACIONAL DE PÓS-GRADUAÇÃO E PESQUISA EM ADMINISTRAÇÃO, 28., 2004, Rio de Janeiro. Anais ENANPAD 2004. Rio de Janeiro: Associação Nacional de Pós-Graduação, 2004. 1CD.

LEITE, Denise. Ameaças pós ranking: sobrevivência das CPAS e da autoavaliação. Avaliação, Campinas; Sorocaba, v. 13, n. 3, p. 833-840, nov. 2008 .

MARTIN, Joanne. Organizational culture: mapping the terrain. London: Sage Publications, 2002.

MARTIN, Joanne; FROST, Peter J.; O’NEILL, Olivia A. Organizational culture: beyond struggles for intellectual dominance. Research Paper Series, Stanford, 2004.

MOKATE, Karen Marie. Convirtiendo el "monstruo" en aliado: la evaluación como herramienta de la gerencia social. Revista do Serviço Público, Brasília, v. 53, n. 1, p. 89-134, jan./mar., 2002.

NIKOS, Michalopoulos. Trends of administrative reform in Europe: towards administrative convergence? International Public Management Review (IPMR), v. 2, n. 2, p 39-53, 2001.

NUNES, Lina Cardoso. As dimensões da autoavaliação institucional: tecendo redes de redes. Ensaio: avaliação de políticas públicas em educação, Rio de Janeiro, v. 14, n. 52, p. 339-348, jul./set. 2006.

PASSOS, Leandro Corrêa. Família, cachaça e máquina sem lubrificação: a 
heterogeneidade cultura revelada em uma Secretaria de Estado de Saúde. In: ENCONTRO DA ASSOCIAÇÃO NACIONAL DE PÓS-GRADUAÇÃO EM ADMINISTRAÇÃO, 29., 2005, Brasília. Anais Enanpad 2005. Rio de Janeiro: Associação Nacional de Pós-Graduação, 2005, 1CD.

PEREZ, Marcelo Monteiro; FAMÁ, Rubens. Métodos de avaliação de empresas e o balanço de determinação. Caderno de Pesquisa em Administração, São Paulo, v. 10, n. 4, p. 47-59, out/dez, 2003.

POLIDORI, Marlis Morosini; FONSECA, Denise Grosso; LARROSA, Sara Fernanda Tarter. Avaliação institucional participativa. Avaliação, Campinas; Sorocaba, v. 12, n. 2, jun., 2007.

RAMOS, Marco Aurélio. Virtualização do trabalho: um estudo de caso na administração pública federal. 2005. Dissertação (Mestrado) - Programa de pós-graduação em Engenharia de Produção - Universidade Federal de Santa Catarina, Florianópolis, 2005.

SCHEIN, Edgar H. Organizational culture and leadership. 4. ed. San Francisco: Jossey-Bass, 2010.

SIQUEIRA, Moema Miranda. Eficácia da administração pública: imposição democrática. Revista de Administração de Empresas, São Paulo, v. 30, n.1, p. 65-72, jan./mar., 1990.

UNIVERSIDADE FEDERAL DE UBERLÂNDIA. Avaliação Sistemática da Universidade Federal de Uberlândia. Uberlândia, 1991.

UNIVERSIDADE FEDERAL DE UBERLÂNDIA. COMISSÃO PRÓPRIA DE AVALIAÇÃO. A autoavaliação institucional na Universidade Federal de Uberlândia - 2001/2005. Uberlândia, 2005.

UNIVERSIDADE FEDERAL DE UBERLÂNDIA. COMISSÃO PRÓPRIA DE AVALIAÇÃO. A autoavaliação institucional na Universidade Federal de Uberlândia. Uberlândia, 2009. Disponível em: < http://www.cpa.ufu.br>. Acesso em: 2 ago. 2012.

UNIVERSIDADE FEDERAL DE UBERLÂNDIA. COMISSÃO PRÓPRIA DE AVALIAÇÃO. A autoavaliação institucional na Universidade Federal de Uberlândia. Uberlândia, 2010. Disponível em: < http://www.cpa.ufu.br $>$. Acesso em: 2 ago. 2012. 
UNIVERSIDADE FEDERAL DE UBERLÂNDIA. COMISSÃO PRÓPRIA DE AVALIAÇÃO. A autoavaliação institucional na Universidade Federal de Uberlândia. Uberlândia, 2012. Disponível em: < http://www.cpa.ufu.br>. Acesso em: 2 ago. 2012.

UNIVERSIDADE FEDERAL DE UBERLÂNDIA. COMISSÃO PRÓPRIA DE AVALIAÇÃO. A autoavaliação institucional na Universidade Federal de Uberlândia. Uberlândia, 2013. Disponível em: < http://www.cpa.ufu.br> . Acesso em: 2 mar. 2013.

VENTURINI, Jonas Cardona; PEREIRA, Breno Augusto Diniz; MORALES, Ronaldo; FLECK, Carolina Freddo; BASTISTELLA JR, Zeno; NAGEL, Mateus de Brito. Percepção da avaliação: um retrato da gestão pública em uma instituição de ensino superior (IES). Revista de Administração Pública [online], v. 44, n. 1, p. 31-53, 2010.

YIN, Robert K. Case study research - design and methods. USA: Sage Publications, 1989.

Ana Elisa de Souza Falleiros - Universidade Federal de Uberlândia Uberlândia | MG | Brasil. Contato: anae20@yahoo.com.br

Márcio Lopes Pimenta - Universidade Federal de Uberlândia Uberlândia | MG | Brasil. Contato: pimenta@fagen.ufu.br

Valdir Machado Valadão Júnior - Universidade Federal de Uberlândia Uberlândia | MG | Brasil. Contato: valdirjr@ufu.br

Artigo recebido em 16 de dezembro de 2013 e aprovado em 2 de julho de 2014. 